\title{
Experimental Study of Improved Loess High Embankment Foundation Jointly by Chemical Materials and Electric Field Treatment
}

\author{
He YIN ${ }^{1,2, a}$, Xue-feng HUANG ${ }^{1,2, b *}$ and Jun-peng ZHOU ${ }^{1,2, c}$ \\ ${ }^{1}$ Department of Civil Engineering, ${ }^{2}$ Chongqing Key Laboratory of Geomechanics \& \\ Geoenvironmental Protection; Logistic Engineering University, Chongqing 401311, P. R. China

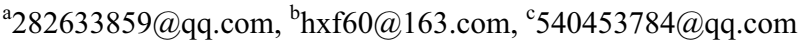

\begin{abstract}
Electric field treatment is a kind of new technology that improves and reinforces soil. Proper amounts of lime and sodium sulfate were added to the soil as stabilizers. Compacted the mixture to meet the predetermined dry density and then imposed a certain intensity of electric field on it. After curing, unconfined compression tests, direct shear tests, high pressure compression tests and collapsibility tests were carried out. The results show that the engineering properties of the improved soils, such as its unconfined compressive strength, shear strength, compressibility, are better than that of the backfill compacted loess. Moreover, collapsibility under the different degree of compaction has been removed. The microstructure and improving mechanism of the improved soils are analyzed using scanning electron microscope (SEM), and the results can provide references for further study and engineering application.

Keywords: alternating electric field; loess high fills; collapsibility; experiment
\end{abstract}

\section{Introduction}

For the past few years, with the coordination development of regional economy and develop-the-west strategy, the urban scale extends continuously in north-western China, and more city constructions (such as Zhengzhou-Xi'an high-speed railway, Lanzhou new district and Yan' an new district) have been carried out. All the construction projects were built on the loess hilly-gully region by filling in the ditch. The filling height can reach up to hundreds of meters. During the construction process, dynamic compaction is a popular method in dealing with loess high filled ground in Yan'an new area. The loess optimum moisture content can't meet the standard for the reason of compaction machinery and constructors, which lead to the compacting factor of 0.7-0.8. The loess compaction has been improved by mixing with curing agent [1]. However, the compacting factor is still not higher than 0.95, which is the standard requested in Code of Foundation Design for Buildings (GB 50007-2011) [2].

In order to satisfy the intensity and compressibility in practical engineering application,

*Corresponding author: hxf60@163.com 
the soil engineering properties are improved and stabilized by being mixed with some chemical modified materials. It has been studied that polymeric and bio-enzymatic consolidators have much better properties than the traditional ones, such as cement, lime, coal ash and slag [3-7]. The application of soil stabilizer GT was investigated to improve mollisol engineering properties [3]. Liu et al. made the experimental research on ionic soil stabilizer ISS for the chemical modification of expansive soil, and revealed the modification mechanism [4]. The soil stabilizer EN-1 was also been studied for the improvement of loess engineering properties and slope slide mechanism [5, 6]. In addition, Wang et al. have studied the SH solidified loess and analyzed the influence of curing period and mixing amount on mechanical and water-physical properties.

Furthermore, external electric field processing technique, a new chemical treatment method, is able to enhance intensity and eliminate collapsibility of compacted loess, especially when compaction degree of loess-filled highway foundation is not up to the control standard. Firstly, loess and modification material (lime), as well as auxiliary material, were mixed completely and compacted together. Then the compacted materials were treated with a certain strength alternating-electric field.

\section{Experimental}

This experiment was carried out according to the methods in Construction Criterion of Collapsible Loess Area (GB 50025-2004) and Standard for Testing Method of Soil (GB/T 50123 - 1999) $[8,9]$. In order to simulate practical construction, the engineering properties of back-filled compacted loess were characterized on the site of Yan'an new district. Physical parameters of the loess are shown in Table 1.

TABLE 1 PHYSICAL PARAMETERS OF THE LOESS

\begin{tabular}{cccccc}
\hline $\begin{array}{c}\text { Natural water } \\
\text { content [\%] }\end{array}$ & $\begin{array}{c}\text { Optimum } \\
\text { water content } \\
{[\%]}\end{array}$ & $\begin{array}{c}\text { Maximum } \\
\text { dry density } \\
{\left[\mathrm{g} \cdot \mathrm{cm}^{-3}\right]}\end{array}$ & $\begin{array}{c}\text { Plastic limit } \\
{[\%]}\end{array}$ & $\begin{array}{c}\text { Liquid limit } \\
{[\%]}\end{array}$ & \begin{tabular}{c} 
Density ratio \\
\hline $9.9 \sim 11.4$
\end{tabular} \\
\hline
\end{tabular}

\subsection{Determine of mixing amount and electric field parameter.}

In order to find the primary affecting factors of the new curing technology and get the best modification scheme, uniaxial compressive strength of improved soil were tested and analyzed by orthogonal experiment from 4 aspects: amount of lime, sodium sulfate, alternating voltage and treatment time (Table 2).

TABLE 2 FACTORS AND LEVELS OF THE ORTHOGONAL TESTS

\begin{tabular}{ccccc}
\hline Level & A & B & C & D \\
\hline 1 & 6 & 1 & 60 & 30 \\
2 & 9 & 1.5 & 70 & 50 \\
3 & 12 & 2 & 80 & 70 \\
4 & 15 & 2.5 & 90 & 90 \\
\hline
\end{tabular}


A, lime $(\%) ; B$, sodium sulfate $(\%) ; C$, alternating voltage $(\mathrm{V}) ; \mathrm{D}$, treatment time $(\mathrm{s})$ 。

In consideration of construction intensity and electricity safety, from the orthogonal test above we see that the best improved soil was produced with $6 \%$ lime, $1 \%$ sodium sulfate, $80 \mathrm{~V}$ alternating voltage and modified for $90 \mathrm{~s}$.

\subsection{Preparation of samples.}

After being well mixed with lime and sodium sulfate as shown in Table 2, loess was prepared to specimens by static force under certain dry density. Then samples were released, and treated under alternating-electric field as shown in the orthogonal design. The curing samples were tested according to the following experiments:

Unconfined compression test: the test was carried out by strain control triaxial compression apparatus SJ-1A (Nanjing electric power automation equipment factory, China) with sample standard of $39.1 \mathrm{~mm} \times 80 \mathrm{~mm}$, without confining pressure, load speed of axial pressure $0.828 \mathrm{~mm} / \mathrm{min}$.

Direct shear test: the test was taken by direct shear apparatus EDJ-1 (Ning Xi soil Instrument Co, Ltd., China), sample standard of $\quad 61.8 \mathrm{~mm} \times 20 \mathrm{~mm}$, quick shearing, shearing rate $2.4 \mathrm{~mm} / \mathrm{min}$ and no drainage, each sample was forced with vertical pressure of $50,100,150$ and $200 \mathrm{kPa}$ separately.

High pressure consolidation and collapsibility test: the test was operated by high-pressure consolidation apparatus GDG, sample standard of $61.8 \mathrm{~mm} \times 20 \mathrm{~mm}$. The test was carried by 11 steps loading with following sequence: $25,50,100,200,300$, $400,600,800,1200,1600$ and $2000 \mathrm{kPa}$. Stability standard of compress variation was less than $0.01 \mathrm{~mm}$ per hour. The double-line method was used to measure collapsibility. Deformation stability analysis of immersion saturated samples was corrected according to the standard.

\section{Results and Discussion}

\subsection{Unconfined compressive strength.}

The unconfined compressive strength of improved loess is better than that of backfill compacted loess (figure 1 (a)), Moreover, the strength of improved loess was found to be four times greater than backfill compacted loess under the different degree of dry destiny. In the curing process, the formation of soil strength mainly occurred in $7 \mathrm{~d}$ and $14 \mathrm{~d}$, then the strength still improved after $21 \mathrm{~d}$, the later strength of samples has been improved by the remaining part of lime (figure 1 (b)). After soaking, the compressive strength of improved loess has been decreased; backfill compacted loess lost the structural strength, and disintegrated rapidly except for the samples of $d_{d}=1.55 \mathrm{~g} / \mathrm{cm}^{3}$. 


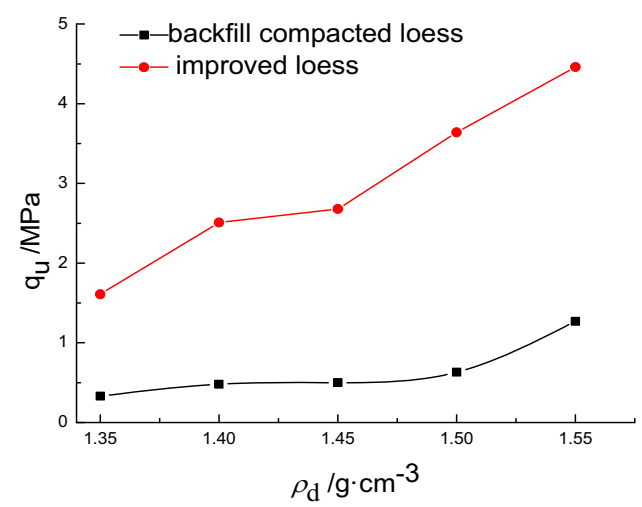

(a)

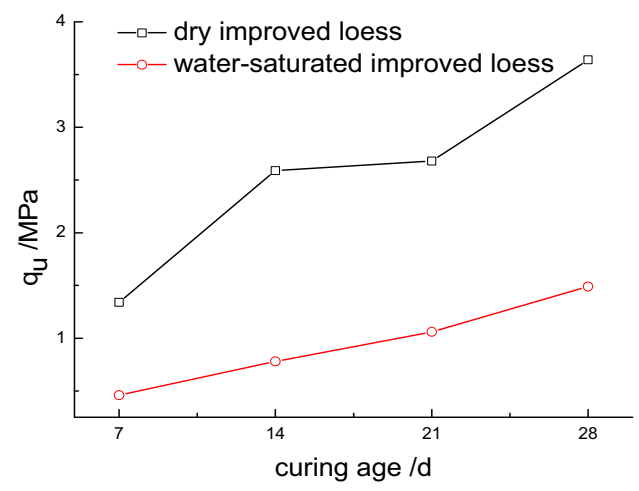

(b)

Fig.1 28d unconfined compressive strength

\subsection{Shearing strength.}

The shear strength parameters of backfill loess and improved loess under different compaction degree are shown in table 3 . Under the same degree of compaction, the cohesive force of improved loess was seven times higher than that of backfill loess, and cohesive force of the two kinds of samples grown with the increase of the compaction and; internal friction angle of improved loess was two times higher than that of backfill loess, internal friction angle values were increased with the degree of compaction, but there was not significantly growth being found. 
TABLE 3 28D SHEAR STRENGTH PARAMETERS

\begin{tabular}{ccccc}
\hline sample & $\begin{array}{c}\text { degree of } \\
\text { compaction } \\
/[\%]\end{array}$ & $\begin{array}{c}\text { dry } \\
\text { density } /\left[\mathrm{g} \cdot \mathrm{cm}^{-3}\right]\end{array}$ & $\begin{array}{c}\text { cohesive } \\
\text { force/[kPa }]\end{array}$ & $\begin{array}{c}\text { Internal } \\
\text { friction } \\
\text { angle } /\left[^{\circ}\right]\end{array}$ \\
\hline improved & 80 & 1.44 & 11.23 & 24.54 \\
loess & 95 & 1.53 & 29.95 & 25.43 \\
& 90 & 1.62 & 32.75 & 27.66 \\
& 95 & 1.71 & 49.60 & 28.82 \\
backfill & 80 & 1.44 & 184.36 & 56.48 \\
compacted & 85 & 1.53 & 235.83 & 57.23 \\
loess & 90 & 1.62 & 300.04 & 57.90 \\
& 95 & 1.71 & 358.43 & 62.07 \\
\hline
\end{tabular}

\subsection{Compressibility.}

The compression deformation parameters of backfill loess and improved loess are shown in table 4. As seen in the table, backfill loess has high compressibility under the condition of low degree, and the compressibility has been decreased with the increase of compaction. However, the compressibility of the improved loess samples were less than 0.1 , belonged to low compressibility soil; and under different dry density, compressibility of samples were slightly different, which shown that the new technique may control uneven settlement of loess foundation under the low degree of compaction.

TABLE 4 28D COMPRESSION DEFORMATION PARAMETERS

\begin{tabular}{|c|c|c|c|c|c|}
\hline sample & $\begin{array}{c}\text { degree of } \\
\text { compaction } \\
{[\%]}\end{array}$ & $\begin{array}{l}\text { dry } \\
\text { density } \\
{\left[\mathrm{g} \cdot \mathrm{cm}^{-3}\right]}\end{array}$ & $\begin{array}{c}\text { coefficient of } \\
\text { compressibility } \mathrm{a}_{1-2} \\
{\left[\mathrm{MPa}^{-1}\right]}\end{array}$ & $\begin{array}{c}\text { modulus of } \\
\text { compression } \mathrm{Es}_{1-2} \\
{[\mathrm{MPa}]}\end{array}$ & $\begin{array}{c}\text { compressi } \\
\text { bility }\end{array}$ \\
\hline \multirow{4}{*}{$\begin{array}{c}\text { improved } \\
\text { loess }\end{array}$} & 70 & 1.26 & 0.88 & 2.01 & high \\
\hline & 80 & 1.44 & 0.38 & 4.59 & middle \\
\hline & 85 & 1.53 & 0.11 & 15.53 & middle \\
\hline & 90 & 1.62 & 0.10 & 16.28 & middle \\
\hline \multirow{4}{*}{$\begin{array}{c}\text { backfill } \\
\text { compacted } \\
\text { loess }\end{array}$} & 70 & 1.26 & 0.075 & 28.72 & low \\
\hline & 80 & 1.44 & 0.063 & 30.02 & low \\
\hline & 85 & 1.53 & 0.058 & 30.43 & low \\
\hline & 90 & 1.62 & 0.050 & 33.56 & low \\
\hline
\end{tabular}




\subsection{Collapsibility.}

As seen in the figure 2, backfill loess has collapsibility expect for the $90 \%$ degree of compaction. The smaller the degree of compaction is, the higher the collapsibility will be, the peak collapsibility coefficient of the backfill loess under $70 \%$ compaction degree is 0.043 , which has reached the middle collapsibility; the collapsibility coefficient of improved loess samples under different condition of the compaction degree were less than 0.015 , the collapsibility were eliminated.

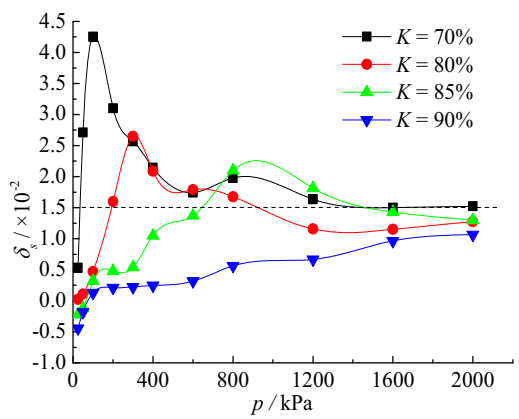

(a) The relationship of $\quad s-p$ of compacted loess

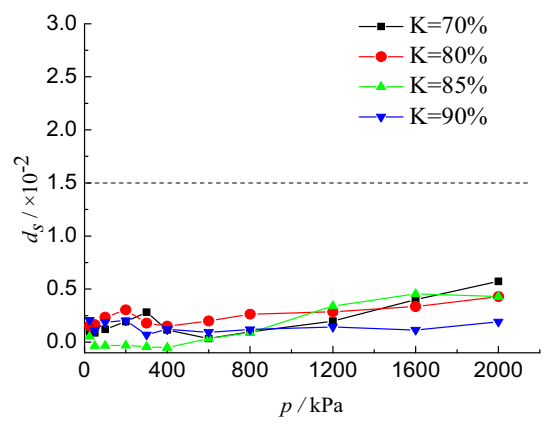

(b) The relationship of $s-p$ of improved loess

Fig. 2 Collapsibility coefficient curves of loess

\subsection{Mechanism of loess solidification.}

Under the electric field, the chemical reaction of compacted mixture is shown as follows:

$$
\mathrm{Na}_{2} \mathrm{SO}_{4}+\mathrm{Ca}(\mathrm{OH})_{2}+2 \mathrm{H}_{2} \mathrm{O} \rightarrow \mathrm{CaSO}_{4} \cdot 2 \mathrm{H}_{2} \mathrm{O}+2 \mathrm{NaOH} .
$$

$\mathrm{NaOH}$, which was produced by the reaction has more alkaline than that of $\mathrm{Ca}(\mathrm{OH})_{2}$, increased $\mathrm{OH}^{-}$concentration in the pore solution and accelerated the chemical reaction rate between the alkali and loess; because of the loess particles polarized under the action of applied electric field, the positive and negative ions in the pore solution make directional movement and form a state of temporary enrichment surrounding the loess particles, which further improves the effective concentration of $\mathrm{OH}^{-}$; meanwhile, part of the electrical energy turns into heat energy and improves the reaction temperature; under the synergy of the temporary high concentration and high reaction temperature, the mixture rapidly reacted inside the loess and formed new products which changed the microstructure of loess. Contrasting figure 3 and figure 4,it was obvious that chemical reaction produced cement 
surrounding the particles, the losser internal structure turned into a mutual coupling by particles of flocculent, the pore of soil particle became smaller due to the filling of cementing material, formed a relatively ideal submicroscopic structure [10].

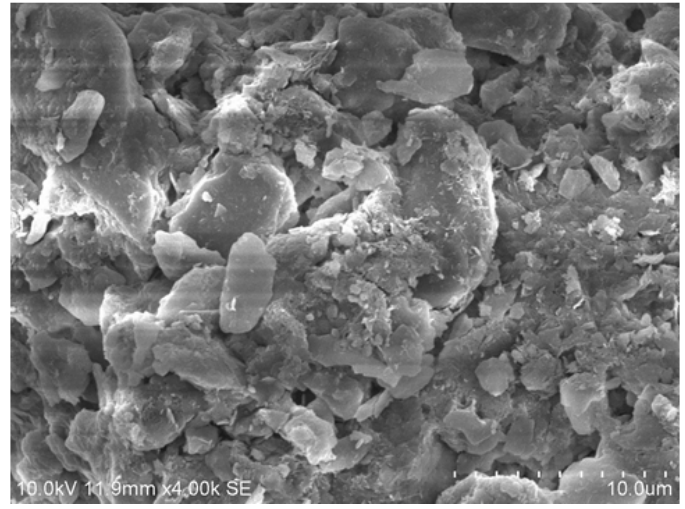

Fig. 3 Scanning photograph magnified 4000 times of compacted loess

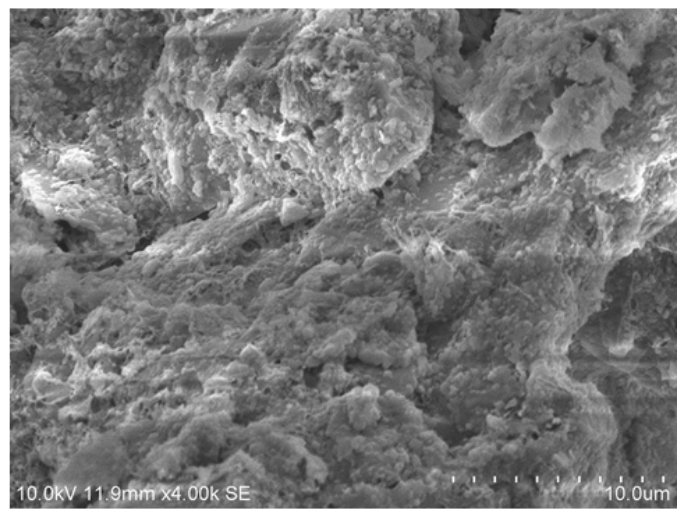

Fig. 4 Scanning photograph magnified 4000 times of improved loess

\section{Summary}

Laboratory test results preliminarily showed that the new technique had better application in consolidating loess. When the compaction degree of loess high fills can't reach the control standards, external electric field processing techniques are able to enhance intensity of compacted loess and eliminate collapsibility. Therefore, the differential settlement would be controlled after construction. In our studies, lime and sodium sulfate were used as modified materials to consolidate loess. The best mix proportion is lime $6 \%$, sodium sulfate $1 \%$. After the treatment of electric field, the compacted mixture was tested from 4 aspects :compressive strength, shearing strength, compressibility and collapsibility. Conclusions are as follows:

-Compared with backfill loess, the improved loess had higher compressive strength, higher shearing strength and lower compressibility. With allowable load less than $2000 \mathrm{kPa}$, it could eliminate collapsibility completely.

- Under the low compaction degree, improved loess has better solidification effect, which is meaningful to loose up requirements for mechanisms and reduce the construction difficulty.

-The mixture fully reacted to produce cement $\mathrm{CaSO}_{4} \cdot 2 \mathrm{H}_{2} \mathrm{O}$, which could avoid residual 
$\mathrm{Na}_{2} \mathrm{SO}_{4}$ resulting into salinized soil. During the curing period, chemical reactions took place smoothly, and the product will be further studied.

\section{Acknowledgments}

The authors would like to thank the Shaanxi Province Science and Technology Plan of Innovation Project (2012KTDZD03-04) and the National Science and Technology Support Program of China (2013BAJ06B00).

\section{References}

1. M. Yang, Y.H. Liu, Experimental study on the incorporation of lime to improve loess performance, J. Subgrade Engineering. 01(2007):53-54.

2. Code of Foundation Design for Buildings (GB 50007-2011).

3. X.W. Fang, S.G. Sun, Z.H. Chen, C.N. Shen and E.C. Xu, Study on engineering properties of improved soil by GT soil firming agent ,J. Rock and Soil Mechanics. 9(2006) :1545-1548.

4. Q.B. Liu, W. Xiang, W.F. Zhang and D.S. Cui, Mechanism of expansive soil improved by ionic soil stabilizer ,J. Rock and Soil Mechanics. 8(2009):2286-2290.

5. L.P. Zhang, X.C. Zhang and Q. Sun, Engineering properties and influencing factors of solidified loess by EN-1solidifying agent ,J. Science of Soil and Water Conservation. 4(2009):60-65.

6. Z.J. Shan, X.C. Zhang, W.X. Zhao, Influence of EN-1 Ionic Stabilizer on soil erosion resistance, J. soil and water conservation. 5(2010):6-9.

7. WANG Yin-mei, LI Cheng, TENG Fei, GAO Li-cheng, New research on chemical solidification of collapsible loess foundation ,J. Applied Mechanics and Materials. 93 (2011):2466-2471.

8. Construction Criterion of Collapsible Loess Area (GB 50025-2004).

9. Standard for Testing Method of Soil (GB/T 50123-1999).

10. X.L. Liao, Y.J. Yang, L. Zhang, B.L. Zhang and C. Liang, An experimental study of acrylamide polymerized solidification of saline soil ,J. Rock and Soil Mechanics. 8(2015):2216-2222. 